OPEN ACCESS

Edited by: Hiroshi Takagi.

Nara Institute of Science and Technology (NAIST), Japan

Reviewed by:

Xinqing Zhao,

Shanghai Jiao Tong University, China

Jun Ishii,

Kobe University, Japan

*Correspondence:

Ying Wang

ying.wang@tju.edu.cn

Specialty section:

This article was submitted to

Microbial Physiology and Metabolism,

a section of the journal

Frontiers in Microbiology

Received: 20 November 2020

Accepted: 22 January 2021

Published: 16 February 2021

Citation:

Zeng $B-X$, Yao $M-D$, Xiao $W-H$,

Luo Y-Z, Wang Y and Yuan Y-J (2021)

Endogenous $2 \mu$ Plasmid Editing

for Pathway Engineering

in Saccharomyces cerevisiae.

Front. Microbiol. 12:631462.

doi: 10.3389/fmicb.2021.631462

\section{Endogenous $2 \mu$ Plasmid Editing for Pathway Engineering in Saccharomyces cerevisiae}

\author{
Bo-Xuan Zeng 1,2, Ming-Dong Yao ${ }^{1,2}$, Wen-Hai Xiao ${ }^{1,2}$, Yun-Zi Luo ${ }^{1,3}$, Ying Wang ${ }^{1,2 *}$ and \\ Ying-Jin Yuan ${ }^{1,2}$

\begin{abstract}
${ }^{1}$ Frontier Science Center for Synthetic Biology and Key Laboratory of Systems Bioengineering (Ministry of Education), School of Chemical Engineering and Technology, Tianjin University, Tianjin, China, ${ }^{2}$ Collaborative Innovation Center of Chemical Science and Engineering (Tianjin), Tianjin University, Tianjin, China, ${ }^{3}$ Department of Gastroenterology, State Key Laboratory of Biotherapy, West China Hospital, Sichuan University, Chengdu, China
\end{abstract}

In Saccharomyces cerevisiae, conventional $2 \mu$-plasmid based plasmid (pC2 $\mu$, such as pRS425) have been widely adopted in pathway engineering for multi-copy overexpression of key genes. However, the loss of partition and copy number control elements of yeast endogenous $2 \mu$ plasmid $(\mathrm{pE} 2 \mu$ ) brings the issues concerning plasmid stability and copy number of pC2 $\mu$, especially in long-term fermentation. In this study, we developed a method based on CRISPR/Cas9 to edit $\mathrm{pE} 2 \mu$ and built the $\mathrm{pE} 2 \mu$ multi-copy system by insertion of the target DNA element and elimination of the original $\mathrm{pE} 2 \mu$ plasmid. The resulting plasmid $\mathrm{pE} 2 \mu \mathrm{RAF} 1$ and $\mathrm{pE} 2 \mu \mathrm{REP} 2$ demonstrated higher copy number and slower loss rate than a $\mathrm{pC} 2 \mu$ control plasmid pRS425RK, when carrying the same target gene. Then, moving the essential gene TPI1 (encoding triose phosphate isomerase) from chromosome to pE2 $\mu$ RAF1 could increase the plasmid viability to nearly $100 \%$ and further increase the plasmid copy number by $73.95 \%$. The expression using pE2 $\mu$ multi-copy system demonstrated much smaller cell-to-cell variation comparing with $\mathrm{pC} 2 \mu$ multi-copy system. With auxotrophic complementation of TP11, the resulting plasmid pE2 $\mu R T$ could undergo cultivation of 90 generations under non-selective conditions without loss. Applying $\mathrm{pE} 2 \mu$ multi-copy system for dihydroartemisinic acid (DHAA) biosynthesis, the production of DHAA was increased to $620.9 \mathrm{mg} / \mathrm{L}$ at shake-flask level in non-selective rich medium. This titer was 4.73 -fold of the strain constructed based on $\mathrm{pC} 2 \mu$ due to the more stable $\mathrm{pE} 2 \mu$ plasmid system and with higher plasmid copy number. This study provides an improved expression system in yeast, and set a promising platform to construct biosynthesis pathway for valuable products.

Keywords: $2 \mu$ plasmid, CRISPR, plasmid copy number, dihydroartemisinic acid, Saccharomyces cerevisiae

\section{INTRODUCTION}

For the high transformation efficiency and easy manipulation, plasmids have been developed as important tools and were widely applied in many kinds of organisms (Mignon et al., 2015; Lian et al., 2016). The multi-copy plasmids are always used to overexpress genes of interest (Kang et al., 2018). In Saccharomyces cerevisiae, conventional $2 \mu$-based plasmid (pC2 $\mu$ ) such as pYES2, 
pRS426, and pESC were widely used multi-copy plasmids for production of recombinant proteins as well as construction of metabolic pathway. For example, overexpression of Syn_ALD (aldehyde dehydrogenase of Synechocystis sp. PCC6803) and CCD2 (carotenoid cleavage dioxygenase of Crocus) by pRS426 increased crocetin production by about 1-fold (Chai et al., 2017). However, like all kinds of multi-copy plasmids, the plasmid viability in cells always depends on the selectivity pressure generated by the medium (with antibiotics or auxotroph medium) (Karim et al., 2013; Lian et al., 2016). In condition without selective pressure, $\mathrm{pC} 2 \mu$ hardly keeps its high copy number and are difficult to be maintained in the host cell (Figure 1A). The loss frequency could reach to about $5 \%$ per generation (Gnügge and Rudolf, 2017), and nearly $50-60 \%$ of the cells lose their plasmid after about $24 \mathrm{~h}$ cultivation in non-selective medium (Christianson et al., 1992). For strain harboring $\mathrm{pC} 2 \mu$ with auxotroph marker, the rich medium such as YPD is not suitable for long-term fermentation because of the loss of the plasmid, although the strain grows faster in these kinds of media; And for that with antibiotic marker, the addition of expensive drugs is inevitable and it is not economic for fermentation of industrial scale.

Plasmid pC2 $\mu$ was derived from the yeast endogenous $2 \mu$ plasmid $(\mathrm{pE} 2 \mu)$ which presents in most wild-type and laboratory $S$. cerevisiae strain (Gnügge and Rudolf, 2017). The $\mathrm{pE} 2 \mu$ is a selfish episomal circular DNA element in S. cerevisiae (Rizvi et al., 2017a). It contains a special replication origin ( $2 \mu$ ori), two FRT sites (FLP1 recognized target site), and sequences encoding four known genes: REP1, REP2, RAF1, and FLP1 (Gnügge and Rudolf, 2017; McQuaid et al., 2017; Rizvi et al., 2017a; see Supplementary Figure 1). FLP1 and both FRT sites are essential for the amplification of $\mathrm{pE} 2 \mu$. This amplification system is based on the FLP1-mediated recombination and follows the special Futcher's model (Futcher, 1986; Rizvi et al., 2017a), thus each plasmid could reproduce more than one copy in one cell cycle to restore the steady-state for plasmid copy number (PCN) under missegregation and consequent perturbations (Rizvi et al., 2017a). Whereas, pC2 $\mu$ plasmid contains only one FRT site. So that $\mathrm{pC} 2 \mu$ cannot be amplified as Futcher's model itself, and the amplification of $\mathrm{pC} 2 \mu$ is not efficient as $\mathrm{pE} 2 \mu$. Therefore, the $\mathrm{PCN}$ of $\mathrm{pC} 2 \mu$ cannot compete with native $\mathrm{pE} 2 \mu$, even though

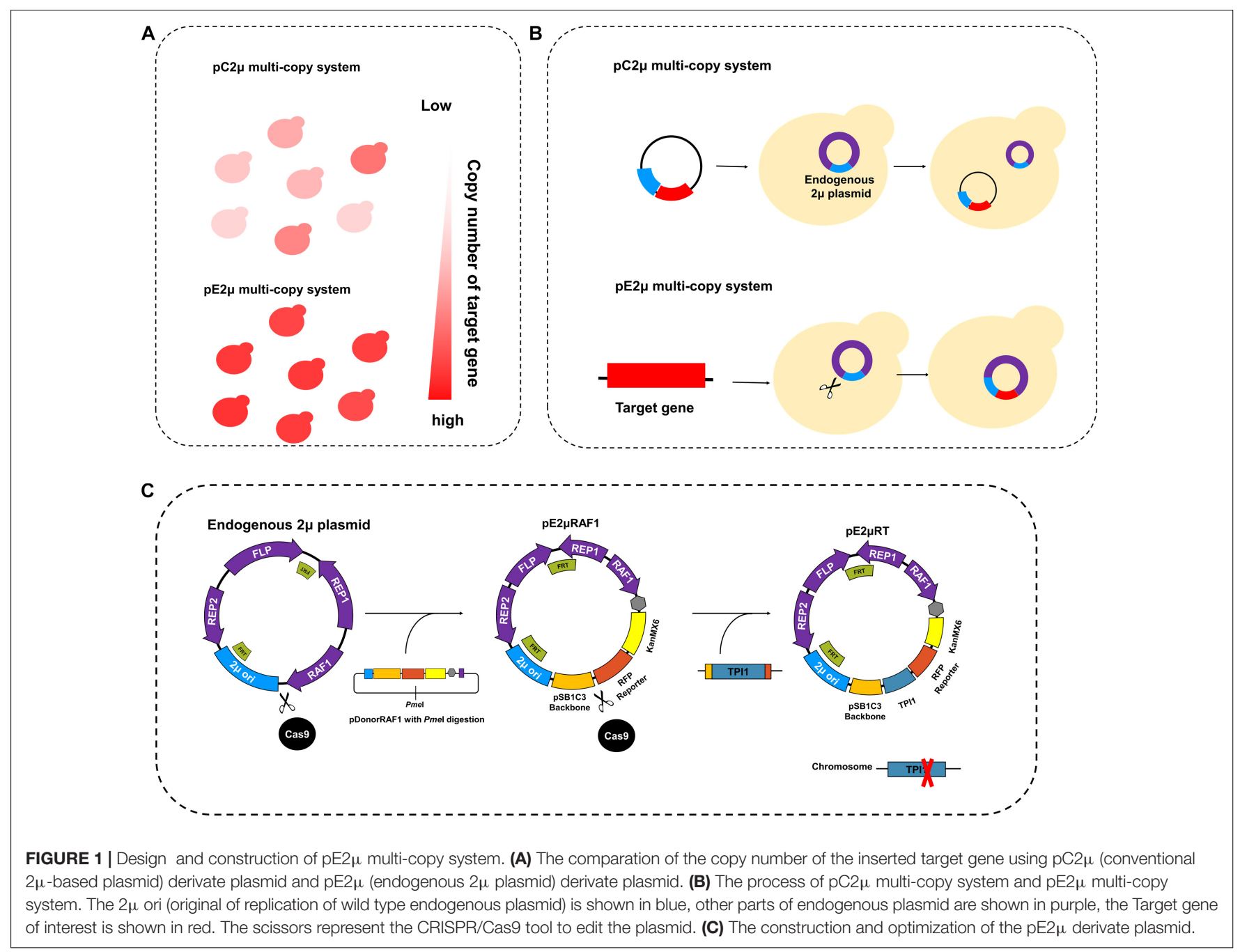


weaken the expression of the selective marker by truncated or weaker promoter could increase the average plasmid copy number of pC2 $\mu$ by eliminating the cells with less plasmid (Karim et al., 2013).

$R E P 1$ and $R E P 2$ are essential for the partition system of $\mathrm{pE} 2 \mu$. REP1 and REP2 form the REP1-REP2 complex which binds to the cis-acting locus (STB locus) (see Supplementary Figure 1) located within the $2 \mu$ ori to ensure equal segregation of plasmids from mother to daughter cells (Gnügge and Rudolf, 2017; Rizvi et al., 2017a); RAF1 is responsible for the regulation of partition and amplification system to keep the plasmid copy number of $\mathrm{pE} 2 \mu$ and minimize the cell-to-cell variations (McQuaid et al., 2017; Rizvi et al., 2017b). Based on the tightly controlled partition system and amplification system described above, pE2 $\mu$ could be segregated equally and the copy number could be restored in some missegregation events, leading to very low loss frequency $(<0.01 \%)$ (Gnügge and Rudolf, 2017). The pC2 $\mu$ only contains $2 \mu$ ori and does not contain REP 1 and $R E P 2$, so the maintenance of $\mathrm{pC} 2 \mu$ has to depend on $\mathrm{pE} 2 \mu$ (Figure 1B). Rising from segregation instability, the loss frequency of $\mathrm{pC} 2 \mu$ is about $50 \%$ per generation in strains without pE2 $\mu$ (Gnügge and Rudolf, 2017). Therefore, to achieve stable and high-level expression of the targeted genes, we intended to employ $\mathrm{pE} 2 \mu$ rather than $\mathrm{pC} 2 \mu$ as an expression vector. Yukie Misumi once constructed the plasmid YHp (Misumi et al., 2019) based on the structure of $\mathrm{pE} 2 \mu$ and applied in the $S$. cerevisiae strain without endogenous $2 \mu$ plasmid. However, because of the similar structure, YHp is not compatible with wild type $\mathrm{pE} 2 \mu$ and was not suitable for application in commonly used laboratory $S$. cerevisiae strain which harboring wild type $\mathrm{pE} 2 \mu$.

In our work, we developed a novel multi-copy plasmid system which based on editing $\mathrm{pE} 2 \mu$ by CRISPR/Cas 9 genome engineering tools (Figures 1B,C). The laboratory strain CEN.PK2-1C was chosen as the host. It contains the natural wild type pE2 $\mu$ plasmid. By using this $\mathrm{pE} 2 \mu$ multi-copy plasmid system, the target gene could be overexpressed more stable and at higher level than using the commonly used pC2 $\mu$ multi-copy plasmid system (Figure 1A). Although the edited pE2 $\mu$ was still lost during long-term cultivation in non-selective medium, the plasmid viability was much higher than that of $\mathrm{pC} 2 \mu$. To further reduce the loss frequency of $\mathrm{pE} 2 \mu$, auxotrophy complementation strategy was applied by introducing the essential gene TPI1 (encoding triose phosphate isomerase) into pE2 $\mu$ by CRISPR/Cas9 system as well as knocking out the TPI1 in the chromosome (Figure 1C). As a result, pE2 $\mu$ plasmid ( $\mathrm{pE} 2 \mu \mathrm{RT}$ ) could be maintained in cells for long-term cultivation. And its PCN was also increased. Although p425RT (pC2 $\mu$ derived plasmid carrying TPI1) in strain without chromosome TPI1 could also be maintained in cell after long-term cultivation in YPD, the average level and stability of p425RT could not compared with that of $\mathrm{pE} 2 \mu \mathrm{RT}$. At last, we applied the method for optimization of the metabolic pathway of dihydroartemisinic acid (DHAA) production in non-selective medium. The production was successfully increased to $620.9 \mathrm{mg} / \mathrm{L}$ which was 4.73-fold higher than the strain using $\mathrm{pC} 2 \mu$ to overexpress the gene of the same biosynthetic pathway.

\section{MATERIALS AND METHODS}

\section{Strains and Medium}

Escherichia coli $\mathrm{DH} 5 \alpha$ was used for construction of all the plasmids and was cultured at $37^{\circ} \mathrm{C}$ in Luria-Bertani (LB) medium ( $1 \%$ tryptone, $0.5 \%$ yeast extract, and $1 \% \mathrm{NaCl}$ ) with $100 \mu \mathrm{g} / \mathrm{ml}$ ampicillin or $34 \mu \mathrm{g} / \mathrm{ml}$ chloramphenicol if necessary. All engineered yeast strains were derived from S. cerevisiae CEN.PK2-1C (Entian and Ktter, 2007) obtained from EUROSCARF (Frankfurt, Germany). The yeast strains were cultured at $30^{\circ} \mathrm{C}$ in YPD medium ( $2 \%$ peptone, $1 \%$ yeast extract, and $2 \%$ glucose) or in synthetic complete (SC) drop-out medium. G418 was added to medium in final concentration of $200 \mu \mathrm{g} / \mathrm{ml}$ if necessary. The strains for DHAA production was derivative from Sc027 (Zeng et al., 2020). All S. cerevisiae strains used in this study were listed in Table 1.

\section{Construction of $\mathrm{pE} 2 \mu$ Derivate Plasmid}

All the plasmids constructed in this study were listed in Table 2. The primer used in this study were listed in Supplementary Table 1.

Three CRISPR/Cas9 plasmid pCasRAF1, pCasREP2, and pCasE2 $\mu$ were constructed based on pRS416 (Supplementary Figure 2). Took the construction of pCasRAF1 for example: $\mathrm{P}_{\text {SNR52 }}$ (RAF1) was amplified from pNA0304 by PCR using primer 18Q3-pSNR52-F and 18Q0b-pSNR52-R; Cassette gRNA.2 $\mu . R A F 1-T_{S U P 4}-T_{C Y C 1}$ was amplified from pNA0304

TABLE 1 | Yeast strains used in this study.

\begin{tabular}{lll}
\hline Yeast Strains & Description & Source \\
\hline CEN.PK2-1C & MAT a; ura3-52, trp1-289, leu2-3,112, his3 $\Delta 1$, & Invitrogen \\
& MAL2-8C, SUC2 & \\
Sc382 & CEN.PK2-1C derivative; $\Delta 2 \mu:: p E 2 \mu R A F 1$ & This study \\
Sc534 & CEN.PK2-1C derivative; $p R S 425 R K$ & This study \\
Sc438 & CEN.PK2-1C derivative; $\Delta 2 \mu:: p E 2 \mu R E P 2$ & This study \\
Sc591 & Sc382 derivative; $\triangle E 2 \mu R A F 1:: p E 2 \mu R T$ & This study \\
Sc594 & Sc591 derivative; $\triangle T P 11($ chromosome)::Ieu2 & This study
\end{tabular}

Sc530 CEN.PK2-1C derivative; p425RT;

$\triangle T P I 1$ (chromosome)::his3

Sc027 CEN.PK2-1C derivative; Zeng et al., 2020

leu2-3,112::KanMX6_PGAL7-CYB5_T TRG19 $(R C)$ -

ERG19(RC)-P $P_{\text {GAL1 } 1}(R C) P_{\text {GAL10 }}-E R G 8-T_{\text {ERG8; }}$

his $3 \Delta 1:: H I S 3$ P P GAL7 $-A L D H 1-T_{T D H 1} T_{\text {ERG12 }}(R C)$ -

ERG12(RC)-P $P_{\text {GAL1 }}(R C) \_P_{\text {GAL } 10}-E R G 10-T_{\text {ERG10; }}$;

ade1 $\triangle:: T_{\text {HMG1 }}(R C)-$ HMG1(RC)-

$P_{\text {GAL1 } 1}(R C) P_{\text {GAL } 10}-I D / 1-T_{\text {IDI1_ADE1; }}$

ura3-52:: $T_{\text {HMG1 }}(R C)$ - $H$ HMG1(RC)-

$P_{\text {GAL1 } 1}(R C) P_{\text {GAL10 }}-$ ERG13-T $T_{\text {ERG13; }}$

trp1-289:: $T_{\text {HMG1 }}(R C)$ - $t$ HMG1(RC)-

$P_{\text {GAL1 }}(R C) P_{\text {GAL10 }}-E R G 20-T_{\text {ERG20_TRP1; }}$

gal1/10/7 $\Delta::$ natA_P $P_{\text {GAL3 }}-C P R 1-T_{\mathrm{CYC1}}$;

Sc341 Sc027 derivative; $\triangle$ gal80::P $P_{\mathrm{CYC1} 1}-$ GAL4-

TGAL4_P PAL7-ADH1-T TDH1;

$\triangle$ KanMX6::P $P_{\mathrm{TDH} 1}-\mathrm{HEM} 1-T_{\mathrm{HEM} 1} P_{\mathrm{PGK} 1}-\mathrm{CT} 1$ -

$T_{\mathrm{CTT} 1 \_} h p h A$

Sc366

$\mathrm{Sc} 343$

Sc341 derivative; p425DCA

Sc341 derivative; $\triangle 2 \mu:: p E 2 \mu D C A$

Sc343 derivative; $\triangle p E 2 \mu D C A:: p E 2 \mu D C A T$

Sc582 derivative; $\triangle T P 11::$ leu2
This study

This study

This study

This study

This study 
TABLE 2 | Plasmids used in this study.

\begin{tabular}{|c|c|c|}
\hline Plasmid & Description & Source \\
\hline pNA0306 & pRS415_PTEF1_Cas9-T $\mathrm{CYC1}$ & Xie et al., 2018 \\
\hline pNA0304 & $p R S 426-P_{\text {SNR52 }}-g R N A-T_{\text {SUP4 }}$ & Xie et al., 2018 \\
\hline pCasRAF1 & pRS416_P $P_{\mathrm{TEF} 1}-$ Cas9-T $T_{\mathrm{CYC} 1} P_{\mathrm{SNR} 52}-g R N A .2 \mu . R A F 1-T_{\mathrm{SUP} 4}-T_{\mathrm{CYC} 1}$ & This study \\
\hline pCasREP2 & pRS416_P $P_{\mathrm{TEF} 1}-\mathrm{CaS9}-T_{\mathrm{CYC} 1} P_{\mathrm{SNR} 52}-g R N A .2 \mu . R E P 2-T_{\mathrm{SUP} 4}-T_{\mathrm{CYC} 1}$ & This study \\
\hline pCasE2 $\mu$ & pRS416_P $P_{\mathrm{TEF} 1}-\mathrm{CaS} 9-T_{\mathrm{CYC} 1 \_} P_{\mathrm{SNR} 52}-\mathrm{gRNA}$.E2 $\mu-T_{\mathrm{SUP} 4}-T_{\mathrm{CYC} 1}$ & This study \\
\hline pDonorRAF1 & pSB1C3_P $P_{\mathrm{TDH} 3}-R F P-T_{\mathrm{ADH} 1}$ KanMX6(RC)_T $T_{\mathrm{PGl} 1}(R C) \_h o m o R A F 1(R C) T_{\mathrm{RAF} 1}(R C)$ & This study \\
\hline pDonorREP2 & $\begin{array}{l}\text { pSB1C3_P } P_{\mathrm{TDH} 3}-R F P-T_{\mathrm{ADH} 1} \text { KKanMX6(RC)_T } \mathrm{CPS} 1(R C) \_h o m o R E P 2(R C) \_T_{\mathrm{REP} 2} \\
(R C)\end{array}$ & This study \\
\hline $\mathrm{pE} 2 \mu \mathrm{RAF} 1$ & 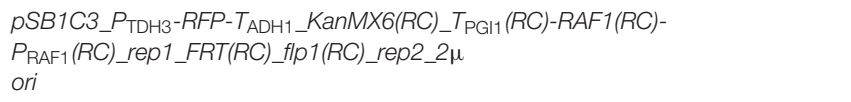 & This study \\
\hline $\mathrm{pE} 2 \mu \mathrm{REP} 2$ & 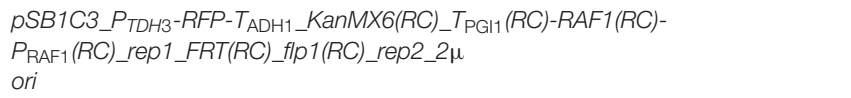 & This study \\
\hline pRS425RK & $p R S 425 \_P_{\mathrm{TDH} 3}-R F P-T_{\mathrm{ADH} 1}(R C) \_K a n M X 6(R C)$ & This study \\
\hline $\mathrm{pE} 2 \mu \mathrm{RT}$ & 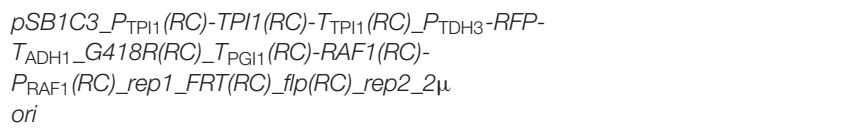 & This study \\
\hline p425RT & $p R S 425 \_P_{\mathrm{TPI} 1}(R C)-\mathrm{TPI}(R C)-T_{\mathrm{TPl} 1}(R C) P_{\mathrm{TDH} 3}-R F P-T_{\mathrm{ADH} 1}$ & This study \\
\hline p425DCA & $\begin{array}{l}\text { pRS425_T } T_{\mathrm{CYC} 1}(R C)-D B R 2(R C)-P_{\mathrm{GAL} 10}(R C)-P_{\mathrm{GAL} 1}-A D S-T_{\mathrm{PGK} 1 \_} P_{\mathrm{GAL7}}{ }^{-} \\
\text {CYP71AV1 }^{*}-T_{\mathrm{ADH} 1}\end{array}$ & This study \\
\hline pDonorDCA & 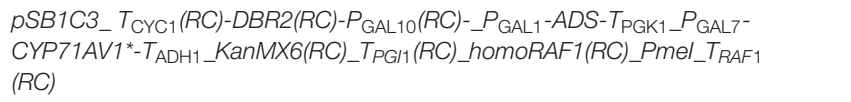 & This study \\
\hline $\mathrm{pE} 2 \mu \mathrm{DCA}$ & 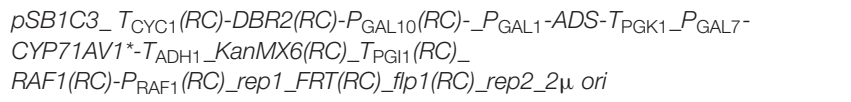 & This study \\
\hline pE2 $\mu$ DCAT & 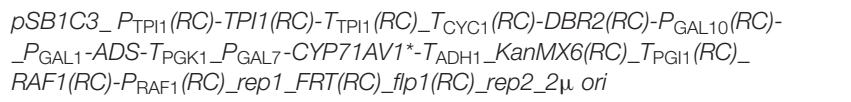 & This study \\
\hline stALG2 & pRS425_ALG9(partial)_P $P_{\mathrm{TDH} 3}-R F P-T_{\mathrm{ADH} 1 \_K a n M X 6(R C)}$ & This study \\
\hline pSB1C3 & Backbone for plasmid construction, CmR & Zeng et al., 2020 \\
\hline pRS416 & Backbone for plasmid construction. Amp, Ura3 & GenBank: U03450.1 \\
\hline
\end{tabular}

The DNA fragment followed by "(RC)" represented the orientation of the DNA fragment was reversed.

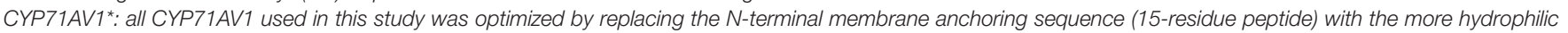
8-residue peptide from bovine (8RP) (Chen et al., 2017).

by PCR using primer 18Q0b-gRNA-F and 18Q3-cyc1t-R; Two DNA fragment were assembled together to constructed cassette $P_{S N R 52-g R N A .2 \mu . R A F 1-T_{S U P 4}-T_{C Y C 1} \text { by OE-PCR }}$ (overlap extension PCR) using primer 18Q3-cyc1t-R and 18Q3pSNR52-F. Cassette $P_{T E F 1}$-cas9- $T_{C Y C 1}$ was amplified by PCR from pNA0306 using primer 18Q3-cas9-F and 18Q3-cas9-R. Cassette $P_{S N R 52-g R N A .2 \mu . R A F 1-T_{S U P 4}-T_{C Y C 1} \text { was digested }}$ by SphI and NotI; Cassette $P_{T E F 1}$-Cas9-T $T_{C Y C 1}$ was digested by KpnI and SphI; pRS416 was digested by KpnI and NotI. Three digested DNA fragments were ligated together by T4 ligase to construct pCasRAF1. pCasREP2 and pCasE2 $\mu$ were constructed in similar way.

Plasmids pDonorRAF1, pDonorREP2, pDonorDCA were donor plasmid. Took the construction of pDonorRAF1 for example: $\mathrm{T}_{G P I 1}$, homoRAF1, $\mathrm{T}_{R A F 1}$ were amplified by PCR from the genome of CEN.PK2-1C using primers 18Q2a-pgiltR/18Q2a-pgilt-F, 18Q2a-homodown-F/18Q2a-homodown-R, 18Q2a-homoup-F/18Q2a-homoup-R. The DNA fragment were assembled to construct T T OE-PCR and amplified using primer 18Q2a-pgilt-F/18Q2ahomoup-R. Cassette $P_{T D H 3}-R F P-T_{\mathrm{ADH} 1}$ was amplified by
PCR using primer 18Q4-pTDH3-F/ 18Q4-adh1t-R. Cassette KanMX6 was amplified by PCR using primer 18Q4a-kanMX6F/18Q4a-kanMX6-R. Cassette T TGI1_homoRAF1_PmeI_T $T_{R A F 1}$ was digested by PstI and XbaI; $P_{T D H 3}-R F P-T_{\mathrm{ADH} 1}$ was digested by EcoRI and XhoI; KanMX6 was digested by XhoI and XbaI; plasmid pSB1C3 was digested by PstI and EcoRI. All 4 digested fragment were ligated together by T4 ligase to construct pDonorRAF1. Donor plasmid pDonorREP2 and pDonorDCA was constructed in similar way.

For construction of the S. cerevisiae strain Sc382, donor plasmid pDonorRAF1 was linearized by PmeI and was cotransformed to CEN.PK2-1C with CRISPR/Cas9 plasmid pCasRAF1 to insert the whole donor DNA into endogenous $2 \mu$ plasmid. The SC-Ura plate with $200 \mathrm{mg} / \mathrm{L}$ G418 was used for selection of the correct transformants. After keeping the plate at $30^{\circ} \mathrm{C}$ for about $72 \mathrm{~h}$, all the transformants were visible. The single colonies were picked up and transferred to SC-Ura plate with $200 \mathrm{mg} / \mathrm{L} \mathrm{G} 418$ and incubated at $30^{\circ} \mathrm{C}$ for $24 \mathrm{~h}$. Then, the colonies were identified by colony PCR. For strain Sc382, the primer pairs $2 \mu$ ori-test-F/BioBrick-R and 18Q-test-5/18Q-test15 were used for verification of the insertion of the donor DNA. 
The primer pair $2 \mu$ ori-test-F/18Q-test- 5 was used for verification of the elimination of all wild type endogenous $2 \mu$ plasmid. The result was used for characterization of the efficiency of the method of editing endogenous $2 \mu$ plasmid by CRISPR/Cas 9 system. After verification, the correct colonies were steaked on 5-FOA (5-Fluoroorotic acid) plate with $200 \mathrm{mg} / \mathrm{L} \mathrm{G} 418$ to lose the pCasRAF1 plasmid.

The process of construction of strain Sc438 and Sc343 were similar to that of strain Sc382. Donor plasmid pDonorREP2 and pCasREP2 were used for co-transformation into CEN.PK2$1 \mathrm{C}$ to construct strain Sc438 (harboring plasmid pE2 $\mu \mathrm{REP} 2$ ); Donor plasmid pDonorDCA and pCasRAF1 were used for co-transformation into CEN.PK2-1C to construct strain Sc343 (harboring plasmid pE2 $\mu \mathrm{DCA}$ ).

To introduce TPI1 to pE2 $\mu$, DNA fragment tpil-1 was amplified from genome of CEN.PK2-1C by PCR using primer 20QRcT-R4/20QRcT-F4, tpi1-2 was amplified from tpi1-1 by PCR using primer 20QRcT-R5/20QRcT-F5, tpi1-3 was amplified from tpi1-2 by PCR using primer 20QRcT-R6/20QRcT-F6. The DNA fragment tpil-3 was co-transformed to strain Sc382 (containing pE2 $\mu$ RAF1) and Sc343 (containing pE2 $\mu$ DCA) with CRISRP/Cas9 plasmid pCasE2 $\mu$ to insert TPI1 into pE2 $\mu$ RAF1 or pE2 $\mu$ DCA to construct strain Sc591 and Sc582.

To delete the TPI1 of chromosome, leu2-1 was amplified from pRS425 by PCR using primer dTPI1-leu2-F1/dTPI1-leu2R1; Then, leu2-2 was amplified from leu2-1 by PCR using primer dTPI1-leu2-F2/dTPI1-leu2-R2; and leu2-3 was amplified from leu2-2 by PCR using primer dTPI1-leu2-F3/dTPI1-leu2R3. DNA fragment leu2-3 was introduced to Sc591 and Sc582 for deletion of TPI1 to construct strain Sc594 and Sc584. For construction of strain Sc530, p425RT was introduced into CEN.PK2-1C and then chromosome TPI1 was deleted by his3.

\section{Plasmid Stability Assay}

To characterize the property of plasmid $\mathrm{pE} 2 \mu$ and $\mathrm{pC} 2 \mu$, strain Sc382, Sc438, Sc534, Sc530, and Sc594 were tested in non-selective YPD medium. The single colony from selective YPD+G418 medium plate was inoculated to $3 \mathrm{ml}$ YPD+G418 medium (for Sc530, the medium was SC-Leu). The saturated culture was re-inoculated to $3 \mathrm{ml} \mathrm{YPD}+\mathrm{G} 418$ medium (for Sc530, the medium was SC-Leu) at an optical density $\left(\mathrm{OD}_{600}\right)$ 0.05 and grown for $10 \mathrm{~h}$ at $30^{\circ} \mathrm{C}$. The culture was at 0 generation and was prepared for characterization. Then the culture was reinoculated to non-selective YPD medium at $\mathrm{OD}_{600}=0.05$ and grown for $10 \mathrm{~h}$ at $30^{\circ} \mathrm{C}$ again to obtain the culture at 5 generation. Then serial sub-cultures were conducted every 5 generation until the 30 th generation. The cultures at 5, 10, 20, and 30 generation were prepared for characterization.

For measurement of the fluorescence of RFP (Red fluorescence protein), plate reader (SpectraMAX M2, Molecular Devices) was used with a $587 \mathrm{~nm}$ excitation filter and a $610 \mathrm{~nm}$ emission filter. The fluorescence of RFP at single cell level was measured by flow cytometer (NovoCyte D2040R). The culture of each generation was diluted and plated on YPD medium and YPD+G418 medium (for Sc530, the selective medium was SCLeu) to calculate the viability of the plasmid by counting the colony number of each plate.

\section{Determination of Plasmid Copy Number (PCN)}

The plasmid copy number ( $\mathrm{PCN})$ was measured by quantitative PCR using the total DNA extracted from the strain. The process of total DNA extraction: the cells was harvest at mid-log phase, and were treated with lysis buffer $(20 \mathrm{mM}$ phosphate buffer at $\mathrm{pH}=7.2,1.2 \mathrm{M}$ sorbitol, $15 \mathrm{U}$ zymolyase) at $37^{\circ} \mathrm{C}$ for $20 \mathrm{~min}$; The total DNA was extracted by boiling the sample for $15 \mathrm{~min},-80^{\circ} \mathrm{C}$ for $15 \mathrm{~min}$ and then boiling again for $15 \mathrm{~min}$ (Lian et al., 2016). The suspension was diluted 10-fold before qPCR analyze. The absolute quantitative method referred to Lee et al. (2006). The plasmid stALG2 (contain ALG9, RFP, KanMX6) and p425DCA (containing ADS) was used for construction of the standard curve. TransStart ${ }^{\circledR}$ Top Green qPCR SuperMix (purchased from TransGen Biotech Co., Ltd) were used for qPCR analyze on Real time fluorescent quantitative PCR (Molarray MA-6000). The primers used for qPCR were listed in Supplementary Table 1.

\section{Fermentation and Measurement of the DHAA}

The medium used for fermentation was YPD medium and FM medium (as our previous work (Zeng et al., 2020)). The FM medium was composed of $8 \mathrm{~g} / \mathrm{L} \mathrm{KH}_{2} \mathrm{PO}_{4}, 15 \mathrm{~g} / \mathrm{L}(\mathrm{NH} 4)_{2} \mathrm{SO}_{4}$, $6.2 \mathrm{~g} / \mathrm{L} \mathrm{MgSO}{ }_{4} \cdot 7 \mathrm{H}_{2} \mathrm{O}, 40 \mathrm{~g} / \mathrm{L}$ glucose, $12 \mathrm{ml} / \mathrm{L}$ vitamin solution, and $10 \mathrm{ml} / \mathrm{L}$ trace metal solution and $10 \mathrm{ml} / \mathrm{L}$ Amino acid solution. Vitamin solution included $0.05 \mathrm{~g} / \mathrm{L}$ biotin, $1 \mathrm{~g} / \mathrm{L}$ calcium pantothenate, $1 \mathrm{~g} / \mathrm{L}$ nicotinic acid, $25 \mathrm{~g} / \mathrm{L}$ myo-inositol, $1 \mathrm{~g} / \mathrm{L}$ thiamine $\mathrm{HCl}, 1 \mathrm{~g} / \mathrm{L}$ pyridoxal $\mathrm{HCl}, 0.2 \mathrm{~g} / \mathrm{L}$ p-aminobenzoic acid, and $2 \mathrm{~g} / \mathrm{L}$ adenine sulfate. Trace metal solution is composed of $5.75 \mathrm{~g} / \mathrm{L} \mathrm{ZnSO}_{4} \cdot 7 \mathrm{H}_{2} \mathrm{O}, 0.32 \mathrm{~g} / \mathrm{L} \mathrm{MnCl}_{2} \cdot 4 \mathrm{H}_{2} \mathrm{O}$, $0.32 \mathrm{~g} / \mathrm{L}$ Anhydrous $\mathrm{CuSO}_{4}, 0.47 \mathrm{~g} / \mathrm{L} \mathrm{CoCl} 2 \cdot 6 \mathrm{H}_{2} \mathrm{O}, 0.48 \mathrm{~g} / \mathrm{L}$ $\mathrm{Na}_{2} \mathrm{MoO}_{4} \cdot 2 \mathrm{H}_{2} \mathrm{O}, 2.9 \mathrm{~g} / \mathrm{L} \mathrm{CaCl} \cdot 2 \mathrm{H}_{2} \mathrm{O}, 2.8 \mathrm{~g} / \mathrm{L} \mathrm{FeSO}{ }_{4} \cdot 7 \mathrm{H}_{2} \mathrm{O}$, and $80 \mathrm{ml} / \mathrm{L}$ EDTA solution (containing $0.5 \mathrm{~mol} / \mathrm{L} \mathrm{Na}_{2} \mathrm{EDTA}$ $\mathrm{pH}=8.0$ ). Amino acid solution is composed of $2 \mathrm{~g} / \mathrm{L}$ methionine, $6 \mathrm{~g} / \mathrm{L}$ tryptophan, $8 \mathrm{~g} / \mathrm{L}$ isoleucine, $5 \mathrm{~g} / \mathrm{L}$ phenylalanine, $10 \mathrm{~g} / \mathrm{L}$ sodium glutamate, $20 \mathrm{~g} / \mathrm{L}$ threonine, $10 \mathrm{~g} / \mathrm{L}$ aspartate, $15 \mathrm{~g} / \mathrm{L}$ valine, $40 \mathrm{~g} / \mathrm{L}$ serine, and $2 \mathrm{~g} / \mathrm{L}$ arginine. The selective medium for Sc366 was FM medium adding $50 \mathrm{mg} / \mathrm{L}$ uracil, the selective medium for Sc343 and Sc584 was FM medium adding $200 \mathrm{mg} / \mathrm{L}$ leucine, and $50 \mathrm{mg} / \mathrm{L}$ uracil and $200 \mathrm{mg} / \mathrm{L}$ G418. The nonselective medium for all strains were YPD medium. To test the productivity of the strains, the single colony from plate was inoculated to selective medium and cultured for $18-24 \mathrm{~h}$ at $30^{\circ} \mathrm{C}$. The seeds were re-inoculated to $3 \mathrm{ml}$ selective medium at $\mathrm{OD}_{600}=0.05$ and cultured for another $18-24 \mathrm{~h}$ at $30^{\circ} \mathrm{C}$. The seed culture of each strain was transferred $250 \mathrm{ml}$ flask containing $25 \mathrm{ml}$ selective medium and flask containing $25 \mathrm{ml}$ non-selective medium at initial $\mathrm{OD}_{600}$ of 0.2 . The cell was grown at $30^{\circ} \mathrm{C}$ with shaking at $200 \mathrm{rpm}$. After $24 \mathrm{~h}, 5 \mathrm{ml}$ dodecane and $20 \mathrm{~g} / \mathrm{L}$ ethanol was added to each flask. The whole fermentation process continued for $120 \mathrm{~h}$ until harvest.

After harvest, the fermentation broth was centrifuged at $12,000 \times g$ for $2 \mathrm{~min}$ and the dodecane phase was collected. And then $50 \mu \mathrm{L}$ organic phase was mixed with $950 \mu \mathrm{L}$ methanol. After filtrated with $0.22 \mu \mathrm{m}$ Nylon 66 filter, the sample was ready for HPLC analysis. The method for HPLC analysis and 
the measurement of DHAA and other intermediates had been reported in previous work (Zeng et al., 2020).

\section{Measurement of Relative mRNA Level}

During the fermentation of Sc366 and Sc343, $1 \mathrm{ml}$ samples was collected at $40 \mathrm{~h}$. Total RNA was extracted from the cell using Yeast RNA kit (Omega bio-tek). The Reverse transcription procedure was used TransScript ${ }^{\circledR}$ First-Strand cDNA Synthesis SuperMix (purchased from TransGen Biotech Co., Ltd). The relative cDNA level of $A D S, C Y P 71 A V 1, D B R 2$ were measured by qPCR. $A L G 9$ was the reference gene, and the result was relative to that of Sc366. The primers used for qPCR were listed in Supplementary Table 1.

\section{RESULTS AND DISCUSSION}

\section{The Construction of $p E 2 \mu$ Multi-Copy System}

In order to construct the multi-copy system, we intended to insert the target DNA into the wild type pE2 $\mu$ plasmid of CEN.PK21C. The pDonor plasmid which harboring homologous arms of wild type $\mathrm{pE} 2 \mu$ was designed to carry target DNA. After linearization, pDonor could be transformed into CEN.PK2-1C and inserted into wild type $\mathrm{pE} 2 \mu$ by homologous recombination to form the recombinant plasmid. Since the incompatibility between the recombinant plasmid and the original wild type pE2 $\mu$ plasmid, the CRISPR/Cas9 plasmid was designed to and enhance the recombination of $\mathrm{pDonor}$ with $\mathrm{pE} 2 \mu$ and eliminate all the original wild type $\mathrm{pE} 2 \mu$ without insertion of $\mathrm{pDonor}$. The resulting strain only contained the recombinant plasmid with multi-copies (Figure 1C).

To insert the target DNA into $\mathrm{pE} 2 \mu$, the site for recombination and the editing target of CRISPR/Cas9 plasmid had to be determined. Beside the four known genes, there are several uncharacterized transcripts transcribed from wild type $\mathrm{pE} 2 \mu$ plasmid (Rizvi et al., 2017a). All the elements described above covered almost the whole plasmid. To avoid the disruption of the plasmid function, only two sites can be chosen as the targets for insertion of foreign DNA fragment: One is at the downstream of the RAF1 (Supplementary Figure 1A), another is at the end of ORF of REP2 (Supplementary Figure 1B). The CRISPR/Cas9 plasmid pCasRAF1 and pCasREP2 were constructed for each target described above. Each of two plasmids encoded both the RNA-guided endonuclease Cas9 and the guide RNA (gRNA) of corresponding (see Supplementary Figure 2). The centromeric plasmid pRS416 was used as the backbone to construct the CRISPR/Cas9 plasmid. Although using multi-copy plasmid such as pRS426 might increase the efficiency of genome or plasmid editing and had been successfully applied for multigenes disruption (Jakounas et al., 2015; Lian et al., 2018), the recombination between pRS426 and endogenous $2 \mu$ plasmid through FRT sites by FLP1 was not desired during the plasmid editing process.

In order to facilitate the introduction of foreign DNA and characterize the modified $2 \mu$ plasmid, we designed two donor plasmids pDonorRAF1 and pDonorREP2. The vector composed of backbone of pSB1C3, KanMX6 for selection, RFP (Red fluorescent protein) cassette as reporter, homologous arms and a terminator (Figure 1). Different from common genome editing by CRISPR/Cas9 system, KanMX6 is necessary selective marker for editing the wild type $2 \mu$ plasmid, because there is no essential gene on it. The terminator would help to finish the transcription of RAF1 or REP2 which might be influenced by inserted DNA. RFP cassette was used for characterization of the modified $2 \mu$ plasmid and two $B s a I$ restriction endonuclease sites flanked by RFP were designed for substitute RFP cassette by other gene of interest. After linearized by PmeI, the donor plasmid pDonorRAF1 or pDonorREP2 was co-transformed with their corresponding CRISPR/Cas9 system plasmid (pCasRAF1 or pCasREP2) into host CEN.PK2-1C. After plasmid editing and recombination, the strain Sc382 (harboring recombinant plasmid pE2 $\mu$ RAF1) and Sc438 (harboring recombinant plasmid pE2 $\mu$ REP2) were constructed (see Figure 1C).

Take the construction of Sc382 for example, we randomly picked 36 single colonies for verification by colony PCR. Among them, 22 colonies (about 61.1\%) were successfully transformed by linearized DNA. And no wild type endogenous $2 \mu$ plasmid remained in these colonies. The yeast plasmids extracted from strain Sc438 and Sc382 could be successfully transformed to

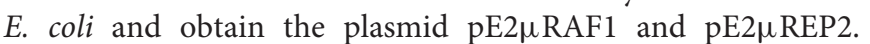
The sequencing result of the $2 \mu$ related part of $\mathrm{pE} 2 \mu \mathrm{RAF} 1$ and $\mathrm{pE} 2 \mu \mathrm{REP} 2$ were consistent with reported endogenous $2 \mu$ plasmid of CEN.PK113-7D (GenBank: CP025735.1) (Piroon et al., 2018), and the editing process was further proved to be successful.

Although CRISPR/Cas9 system has been successfully applied in genome editing, it was the first attempt to edit the multicopy plasmid. Comparing with the efficiency of genome editing which was almost 100\% (Jakounas et al., 2015; Generoso et al., 2016), the efficiency of multi-plasmid editing was not as high as that. Multi-copy target sequences and the special amplification system of endogenous $2 \mu$ plasmid (Gnügge and Rudolf, 2017) made the work of CRISPR/Cas9 system not easy. Some strategies for optimization CRISPR/Cas9 system increasing might be helpful for increasing the efficiency of $2 \mu$ plasmid editing, such as increasing activity of cleavage by using Cas9 variants (Bao et al., 2014), changing the promoter for optimization of gRNA expression (Gao and Zhao, 2013), and facilitating gRNAtransient expression system (Easmin et al., 2019). Anyway, the method for plasmid editing applied in this work had been proved to be viable and successful to insert the target DNA element into the $\mathrm{pE} 2 \mu$ to form a new recombinant multi-copy plasmid and eliminate the original $\mathrm{pE} 2 \mu$ plasmid.

\section{Characterization of the Plasmids From pE2 $\mu$ Multi-Copy System}

To characterize the property of $\mathrm{pE} 2 \mu$, we chose $\mathrm{pC} 2 \mu$ plasmid pRS425RK as a control. pRS425RK was constructed based on conventional $2 \mu$ plasmid pRS425. RFP cassette and KanMX6 of pRS425RK were used for characterization. The strain Sc534 which harboring pRS425RK was constructed. We evaluated the stability of Sc382 and Sc438 compared with control strain 
Sc534 by plasmid stability assay. The strains were culture in YPD media without selective pressure and were transferred to fresh media every 5 generation. The fluorescence at single cell level was measured at 5, 10, 20, and 30 generation (Figure 2). Under condition with selective pressure (at 0 generation), the cells of the strains with $\mathrm{pE} 2 \mu$ (Sc382 and Sc438) showed less cell-to-cell variation (smaller CV \%) than that with pRS425RK (Sc534) (Figure 2A). The average fluorescence of strains Sc438 and Sc382 was also 3.42 to 3.67 -fold higher than that with pRS425RK (Supplementary Figure 3). The cell growth of Sc382 and Sc438 higher than that of Sc534 after $48 \mathrm{~h}$ fermentation in condition with selective pressure (Figure 2C). The PCN of Sc382 (pE2 $\mu$ RAF1) achieved 10.4 and was about 1.67-fold higher than that of Sc534, while the average PCN of Sc438 (pE2 $\mu$ REP2) was 10.8 copies and also higher than that of Sc534 (Figure 2D).

After culturing in the condition without selective pressure, all the strains began to lose the plasmid. Nearly $94 \%$ cells of the Sc534 (pRS425RK) lost their plasmid after culture of 10 generation and hardly to find cells with plasmid after 20 generation. The frequency of plasmid lost is lower at strain Sc382 and Sc438. Only about $20-23 \%$ of the cells lost their plasmid before 10 generation, but $88-89 \%$ of the cells had lost their plasmid until 30 generation (Figure 2B). There was no significant difference in PCN and plasmid stability between pE2 $\mu$ RAF1 and $\mathrm{pE} 2 \mu \mathrm{REP} 2$. Although the stability of the strain with $\mathrm{pE} 2 \mu$ is higher than the strain with conventional $2 \mu$ plasmid, it is much lower than the wild type endogenous $2 \mu$ plasmid.

The PCN control system of $2 \mu$ plasmid based on RAF1 and REP1-REP2 complex could tightly control its copy number (McQuaid et al., 2017; Rizvi et al., 2017a). REP1-REP2 complex is responsible for stability of plasmid and repression of FLP to control the PCN; RAF1 could repress the formation of REP1$R E P 2$ to derepress the expression of FLP1 to increase the PCN (Rizvi et al., 2017b). The pC2 $\mu$ is out of this copy number control

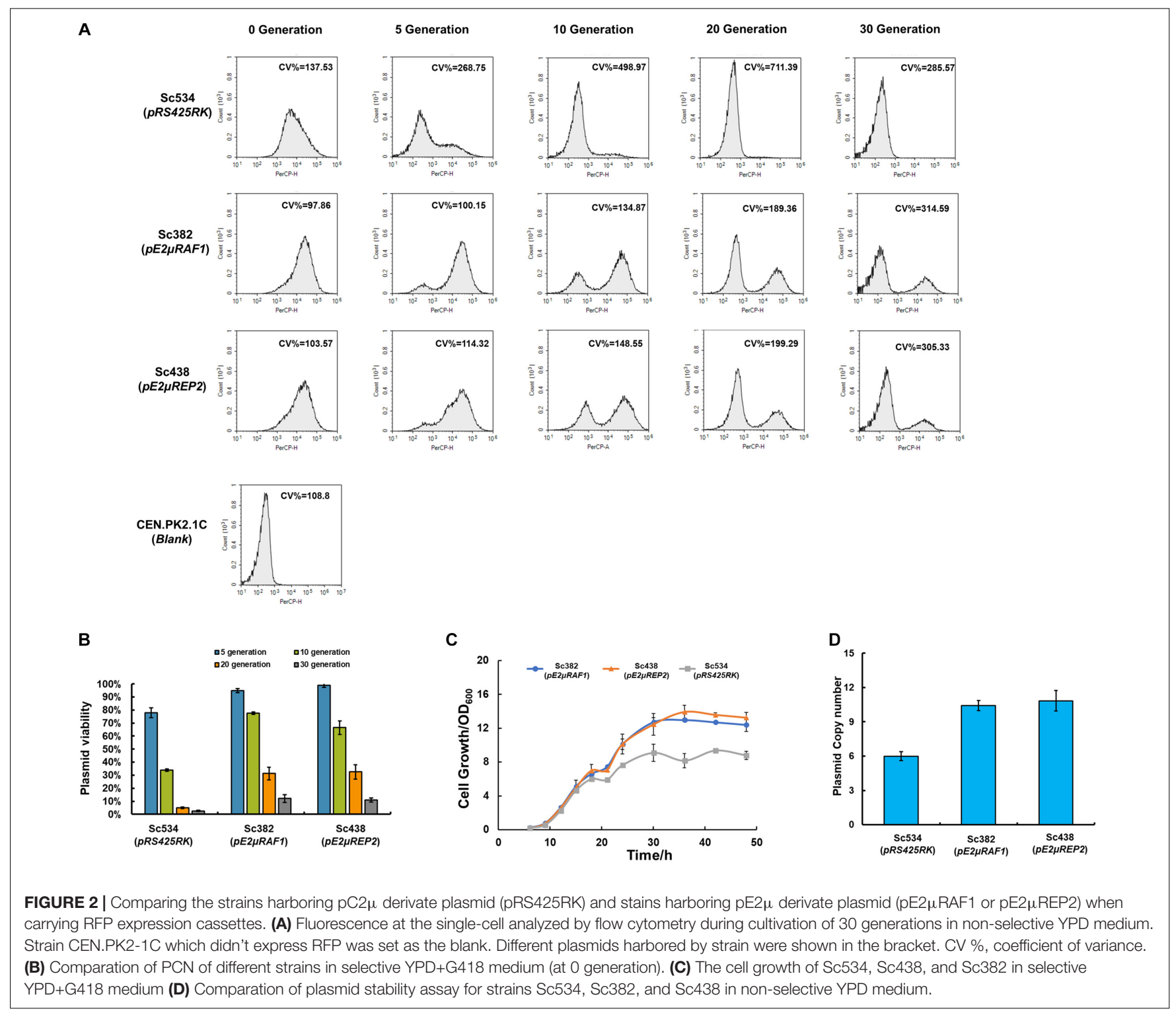


system, and difficult to keep the stability and equality even in condition with selective pressure. While, the $\mathrm{pE} 2 \mu$ could facilitate the PCN control system to keep its equality of PCN, and is more stable. The insertion of foreign DNA didn't disrupt any known genes on the $2 \mu$ plasmid, but it might influence the expression level of these genes or other unknown function transcripts to reduce the stability of $2 \mu$ plasmid. In spite of that, $\mathrm{pE} 2 \mu$ is might be a better choice than $\mathrm{pC} 2 \mu$ plasmid to overexpress the genes of interest by increasing its copy number. Strain Sc382 was chosen as the host for further optimization.

\section{Optimization of pE2 $\mu$ Multi-Copy System by Auxotrophy Complementation of Essential Gene TPI1}

The maintenance of the plasmid in the cell is very important for long-term fermentation. To eliminate the plasmid loss of $\mathrm{pE} 2 \mu$ in non-selective condition, an auxotroph marker based on essential gene TPI1 was constructed. Gene TPI1 encodes triose phosphate isomerase which is required for growth on glucose and makes up about $2 \%$ of the soluble cellular protein (Scott and Baker, 1993). The strategy of using essential gene to substitute the one on the chromosome to construct the selective pressure-free system and optimize the plasmid system had been used in E. coli (Chen, 2012; Kang et al., 2018). However, fewer studies focused on the optimization of plasmid in $S$. cerevisiae. CRISPR/Cas9 plasmid pCasE2 $\mu$ was constructed for insertion of TPI1 into plasmid pE2 $\mu$ RAF1 of strain Sc382. The editing target of pCasE2 $\mu$ was on the pSB1C3 backbone of pE2 $\mu$ RAF1. After insertion of TPI1 into pE2 $\mu$ RAF1 (the resulting plasmid was $\mathrm{pE} 2 \mu \mathrm{RT}$ ) and deletion of native TPI1 in chromosome by his 3 , the strain Sc594 was constructed (see Figure 1C). For comparation, strain Sc530 which harboring plasmid p425RT (based on pRS425 and containing TPI1) and the deletion of the native TPI1 was constructed. Compared with wild type CEN.PK2-1C, both Sc594 and Sc530 showed similar cell growth for $48 \mathrm{~h}$ fermentation in non-selective YPD medium (see Figure 3B). The plasmid viability of both strains was evaluated by a very long-term cultivation (90 generation) without any selective pressure in YPD medium. For both strains, the viability was nearly $100 \%$ (see Figure 3D), and no plasmid-free cell was found at 90 generation, all cells plated on YPD plate were expressing RFP (see Supplementary Figure 4A). TPI1 was the key enzyme for both glycolysis and gluconeogenesis process, cells without TPI1 are inviable (Giaever et al., 2002). For strain Sc594, after moving the TPI1 from chromosome to plasmid, TPI1 became an auxotrophy selective marker of the plasmid. Since TPI1 is an essential gene, this auxotrophy selective marker have no requirement of the condition, and the plasmid-free cells was inviable. On the contrary, for strain Sc382 or Sc438, the selective marker of their plasmid was KanMX6, the plasmid only could be kept in condition with G418, the cells would lose the plasmid in non-selective YPD medium. Therefore, the plasmid viability of Sc594 or Sc530 was shown higher than that of Sc382 or Sc438. Optimization of the plasmid by auxotrophy complementation of essential gene TPI1 could also increase the PCN of both $\mathrm{pC} 2 \mu$ and $\mathrm{pE} 2 \mu$ derivate plasmid. The PCN of $\mathrm{pE} 2 \mu \mathrm{RT}$ in
Sc594 achieved to about 18.3 and was 1.76-fold higher than that of pE2 $\mu$ RAF1 in Sc382 at 0 generation; while the PCN of p425RT in Sc530 was also increased to 10.8 and was 1.80 -fold higher than that of pRS425RK in Sc534 (Figure 3A). During the long-term cultivation in non-selective medium, the $\mathrm{pE} 2 \mu$ derivate plasmid showed higher stability in PCN and less cellto-cell variation comparing with $\mathrm{pC} 2 \mu$ derivate plasmid. The CV\% of Sc530 was increased by 37\% from 132.32 (0 generation) to 182.59 (90 generation) (Figure 3C) and the average PCN of p425RT decreased by $38.2 \%$ to 6.67 (Figure 3A); While CV \% of Sc594 was only increased by $15.90 \%$ from 94.95 to 110.05 (90 generation) and lower than that of Sc530 in any generations (see Figure 3B). The average PCN of pE2 $\mu$ RT only decreased by $8.74 \%$ to 16.7 after cultivation of 90 generation in nonselective medium (see Figure 3A), the average expression level of the RFP in Sc594 was obviously higher than that of Sc530 (Supplementary Figure 4B). The stability of the expression for the target gene using optimized $\mathrm{pE} 2 \mu$ multi-copy system was proved to undergo very long-term cultivation. The strategy of introduction of TPI1 into plasmid to substitute the native TPI1 was proved to optimize both $\mathrm{pC} 2 \mu$ derivate plasmid and $\mathrm{pE} 2 \mu$ derivate plasmid. And the resulting plasmid pE2 $\mu$ RT showed higher PCN and less cell-to-cell variations. Therefore, pE2 $\mu$ RT was thought to be better choice for overexpression of target genes in high copy.

\section{Application pE2 $\mu$ Multi-Copy System for DHAA Production}

To demonstrate $\mathrm{pE} 2 \mu$ could be applied for optimization of metabolic pathway, dihydroartemisinic acid (DHAA) biosynthesis was chosen as an example. DHAA is the precursor of the anti-malaria drug artemisinin (Paddon and Keasling, 2014). The biosynthesis pathways of DHAA (see Figure 4A) starts from farnesyl pyrophosphate. In this pathway, $A D S$, $C Y P 71 A V 1$, and DBR2 are the key genes for biosynthesis of DHAA and are thought to be overexpressed in high level to increase the production of DHAA. Several studies about the biosynthesis of DHAA in S. cerevisiae had been reported (Yansheng et al., 2008; Chen et al., 2017; Zeng et al., 2020). All of these works facilitated $\mathrm{pC} 2 \mu$ based plasmids such as pESC-LEU, pRS425, pYES260 to overexpress the key genes of the biosynthesis pathway. Therefore, $\mathrm{pE} 2 \mu$ multi-copy system was thought to be helpful for further enhancing the biosynthesis of DHAA by optimization of the plasmid.

In this work, Sc366 was used as the control strain. Sc366 harbored plasmid p425DCA which was constructed based on pRS425 and contained three key genes ADS, CYP71AV1, and DBR2. Strain Sc343 harbored pE2 $\mu$ plasmid pE2 $\mu$ DCA which contained ADS, CYP71AV1, and DBR2. And Sc584 was modified from Sc343 by introducing the TPI1 to pE2 $\mu$ DCA (resulting plasmid was plasmid pE2 $\mu \mathrm{DCAT}$ ) to substitute the native chromosome TPI1. In non-selective rich medium (YPD medium), nearly $82 \%$ cells of Sc366 lost their plasmid during the fermentation (see Figure 4C), the production of DHAA was only $131.0 \mathrm{mg} / \mathrm{L}$ (Figure 4B); For strain Sc343 which harbored plasmid pE2 $\mu \mathrm{DCA}$, only $29.8 \%$ of cells lost their plasmid, and 


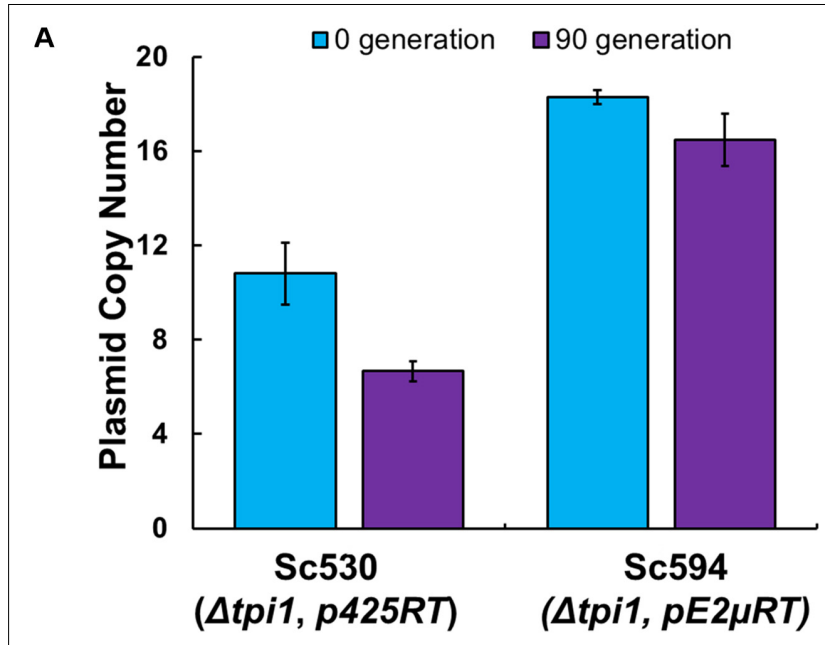

C
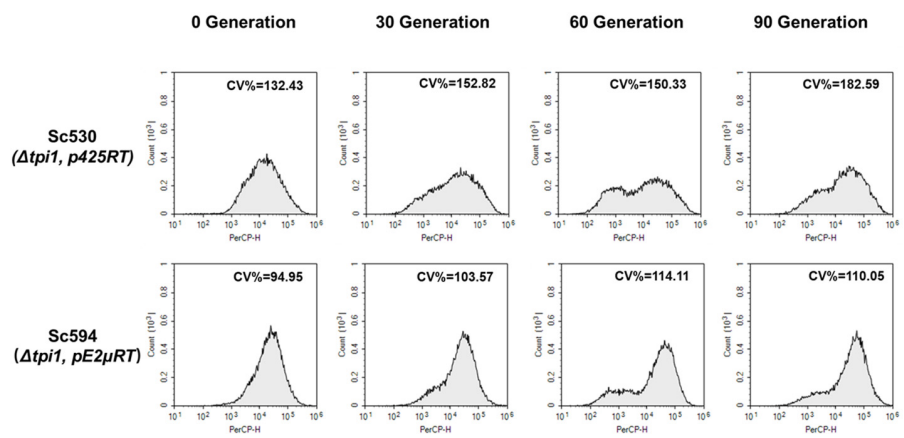

B

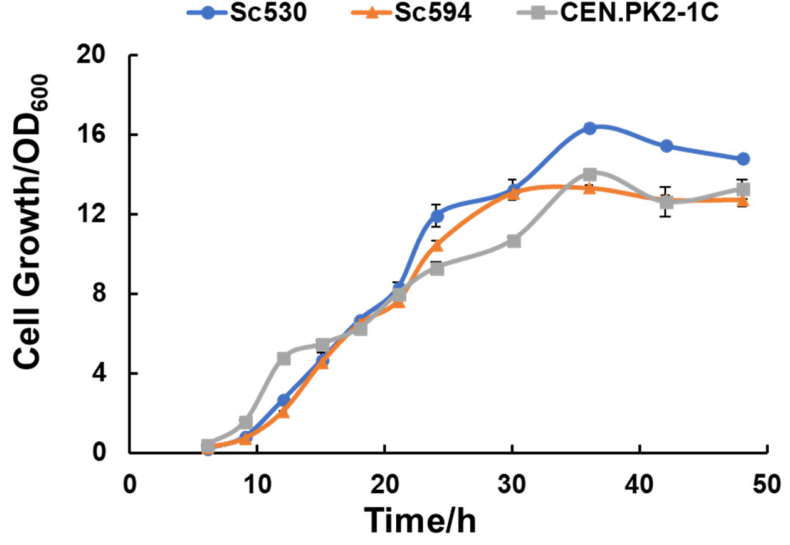

D

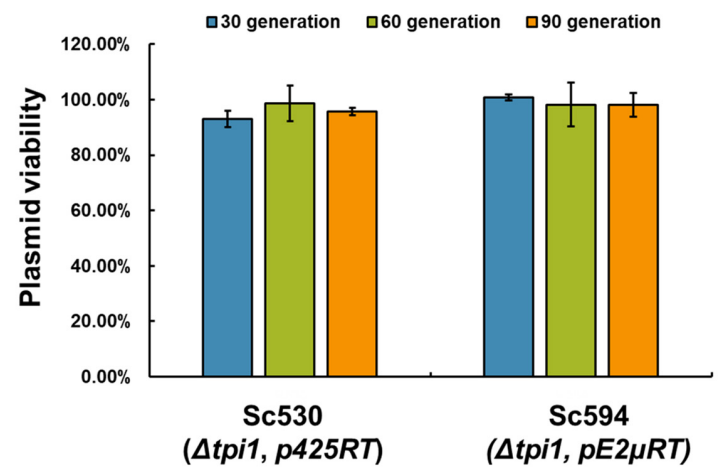

FIGURE 3 | Effect of TPl1 auxotrophic complementation on strains Sc594 and Sc530 harboring pC2 $\mu$ and pE2 $\mu$ derivate plasmids, respectively. (A) Comparation of PCN for strain Sc530 and Sc594 before (0 generation) or after (90 generation) a very long-term cultivation in non-selective YPD medium (B) Cell growth of strain Sc594 and Sc530 and the wild type CEN.PK2-1C in non-selective YPD medium. (C) Fluorescence at the single-cell analyzed by flow cytometry during cultivation of 90 generations. (D) The plasmid stability assay for strain Sc594 and Sc530.
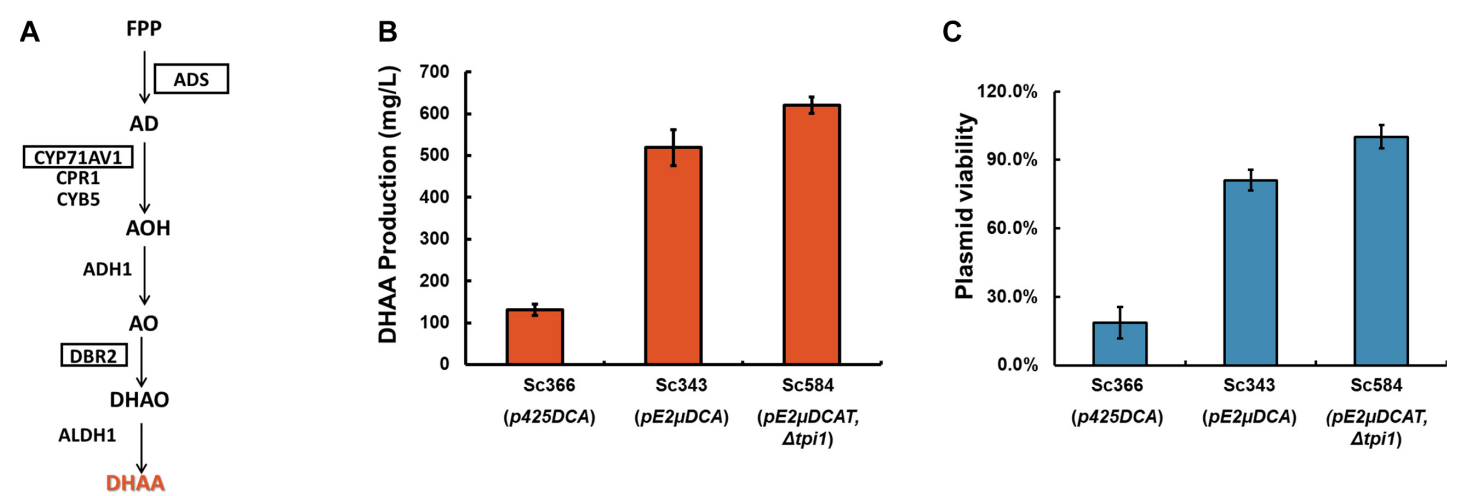

FIGURE 4 | Comparation of the effects of $\mathrm{pC} 2 \mu$ and $\mathrm{pE} 2 \mu$ multi-copy system on DHAA production. (A) The biosynthesis pathway of DHAA. FPP, Farnesyl pyrophosphate; $\mathrm{AD}$, amorpha-4,11-diene; $\mathrm{AOH}$, artemisinic alcohol; $\mathrm{AO}$, artemisinic aldehyde; $\mathrm{DHAO}$, dihydroartemisinic aldehyde; DHAA, dihydroartemisinic acid; AA, artemisinic acid; ADS, amorphadiene synthase; CYP71AV1, amorphadiene P450 oxidase; CPR1, P450 cytochrome reductase from A. annua; CYB5, cytochrome b5 from $A$. annua; ADH1, artemisinic alcohol dehydrogenase of $A$. annua; $D B R 2$, artemisinic aldehyde $\triangle 11(13)$ reductase of $A$. annua; $A L D H 1$, artemisinic aldehyde dehydrogenase of $A$. annua. ADS, CYP71AV1, DBR2 (highlighted in the frame) were genes overexpressed by plasmid systems. (B) The DHAA production of strain Sc366, Sc343 and Sc584 in YPD medium. (C) The plasmid viability of strains Sc366, Sc343 and Sc584 which were measured at the end of the fermentation in YPD medium. 
the production achieved to $519.2 \mathrm{mg} / \mathrm{L}$ and was 3.96-fold higher than that of strain harboring $\mathrm{pC} 2 \mu$ plasmid (Figures $4 \mathrm{~B}, \mathrm{C}$ ); After optimization with substitution the location of essential TPI1, the resulting strain Sc584 didn't lose the plasmid, and got higher production to $620.9 \mathrm{mg} / \mathrm{L}$. The average copy number of Sc366, Sc343, and Sc584 was 3.33, 6.57, and 9.32, respectively (Supplementary Figure 5). The relationship of mRNA levels of the key genes for different strain was consist with the result of average copy number (Supplementary Figure 6). Comparing with Sc594, the PCN of Sc584 was decreased by about $44.5 \%$. The plasmid stability might be influenced by the overexpression of CYP71AV1 and CPR1, or the rapid accumulation of AA (artemisinic acid) and DHAA. It was consistent with the result of the work of Amyris (Paddon et al., 2013) which found the effect on the plasmid by overexpression of CYP71AV1 or accumulation of product.

The medium with selective pressure for yeast was auxotrophic synthetic medium or the rich medium. However, the nonselective pressure rich medium such as YPD or YPG would help strain to produce more production even the plasmid was not stable (Ro et al., 2008) during the large scale and long-time fermentation (Wang et al., 2017). In rich medium, approximately half of the proteome mass saved by amino acid could be redirected to protein engaged in translation (Bjrkeroth et al., 2020). It could promote cell growth and might increase the expression of the target gene. Therefore, the optimized $\mathrm{pE} 2 \mu$ multi-copy system platform was suitable for $S$. cerevisiae to overexpress target gene in non-selective rich medium with higher PCN and has the patent for optimization of biosynthetic pathway and maximize the biochemical production.

In this work, we developed the toolbox for editing the $2 \mu$ plasmid to maintain and increase the copy number of the target gene for all $S$. cerevisiae with or without wild type $\mathrm{pE} 2 \mu$ (see Supplementary Figure 7). For strain without $\mathrm{pE} 2 \mu$, the plasmid pE2 $\mu$ RAF1 or pE2 $\mu$ REP 2 could be used as the backbone directly. The target DNA elements could be inserted into these plasmids in vitro or in vivo. For strains with wild type $\mathrm{pE} 2 \mu$, the CRISPR/Cas9 plasmid could be used for editing the wild type $\mathrm{pE} 2 \mu$ plasmid. And the donor plasmid pDonorRAF1 or pDonorREP2 could be used as the backbone to harbor the target DNA. The example of DHAA production in our work proved that this method could successfully increase the copy number of the target gene. The strain Sc594 was constructed as a convenient chassis for overexpression of the target gene efficiently (Supplementary Figure 7). The pE2 $\mu$ RT could also undergo a serial of editing steps to insert the DNA element of interest. During these steps, extra selective marker is not necessary to insert into the plasmid, and the whole editing process of $\mathrm{pE} 2 \mu$ is same to the process for editing the genome of chromosome which had been widely used for optimization of S. cerevisiae. And higher copy number of the inserted genes could be easily obtained.

Considering the very low loss frequency of wild type $\mathrm{pE} 2 \mu$, the performance of the loss frequency for $\mathrm{pE} 2 \mu \mathrm{RAF} 1$ and $\mathrm{pE} 2 \mu \mathrm{REP} 2$ was unexpected. Although introduction of essential gene TPI1 to substitute the original TPI1 on chromosome could eliminate the plasmid-free cells during the long-term cultivation, the reason for the increasing loss of the plasmid leaded by insertion of foreign
DNA into wild type pE2 $\mu$ plasmid was still needed to be studied. The future study might focus on the regulation of the gene or unknown transcript units of $\mathrm{pE} 2 \mu$ plasmid and the stability and the copy number of the $\mathrm{pE} 2 \mu$ might be further increased.

\section{CONCLUSION}

In this work, the endogenous $2 \mu$ plasmid had been successfully and perfectly edited by CRISPR/Cas9 system and the donor plasmid. The foreign gene could be inserted to $2 \mu$ plasmid in higher copy number for overexpression. The resulting plasmid pE2 $\mu$ had higher PCN and higher stability than the conventional $2 \mu$ based plasmid. In single cell level, the distribution of $\mathrm{pE} 2 \mu$ in each cell was more balanced than $\mathrm{pC} 2 \mu$ plasmid. Taking these advantages, $\mathrm{pE} 2 \mu$ was applied for the heterologous biosynthesis of DHAA, and increased the production titer by 4.73 -fold higher than that of control. This study showed the potential of $\mathrm{pE} 2 \mu$ for optimization of metabolic pathway by stable and efficiently overexpressing a serial of genes.

\section{DATA AVAILABILITY STATEMENT}

The original contributions presented in the study are included in the article/Supplementary Material, further inquiries can be directed to the corresponding author.

\section{AUTHOR CONTRIBUTIONS}

$\mathrm{B}-\mathrm{XZ}$ and $\mathrm{YW}$ conceived the study as well as participated in strain construction and carried out the molecular genetic studies. B-XZ and W-HX participated in fermentation. Y-JY, M-DY, Y-ZL, and $\mathrm{W}$-HX participated in design and coordination of the study as well as helped to draft the manuscript. YW supervised the whole research and revised the manuscript. All the authors read and approved the final manuscript.

\section{FUNDING}

This work was supported by the National Key Research and Development Program of China (2019YFA0706900 and 2018YFA0900702), the National Natural Science Foundation of China (21621004 and 32071415), and New Drug Creation Manufacturing Program (2019ZX09J19105).

\section{ACKNOWLEDGMENTS}

We are grateful to thank Dr. Jian-ting Zhou from Tianjin University for their kind discussion.

\section{SUPPLEMENTARY MATERIAL}

The Supplementary Material for this article can be found online at: https://www.frontiersin.org/articles/10.3389/fmicb.2021. 631462/full\#supplementary-material 


\section{REFERENCES}

Bao, Z., Xiao, H., Liang, J., Zhang, L., Xiong, X., Sun, N., et al. (2014). A Homology Integrated CRISPR-Cas (HI-CRISPR) system for one-step multigene disruptions in Saccharomyces cerevisiae. Acs Synthetic Biol. 4, 585-594. doi: 10.1021/sb500255k

Bjrkeroth, J., Campbell, K., Malina, C., Yu, R., and Nielsen, J. (2020). Proteome reallocation from amino acid biosynthesis to ribosomes enables yeast to grow faster in rich media. Proc. Natl. Acad. Sci. U.S.A. 117, 21804-21812. doi: 10.1073/pnas.1921890117

Chai, F., Wang, Y., Mei, X., Yao, M., Chen, Y., Liu, H., et al. (2017). Heterologous biosynthesis and manipulation of crocetin in Saccharomyces cerevisiae. Microb. Cell Fact. 16:54.

Chen, R. (2012). Bacterial expression systems for recombinant protein production: E. coli and beyond. Biotechnol. Adv. 30, 1102-1107. doi: 10.1016/j.biotechadv. 2011.09.013

Chen, X., Zhang, C., and Too, H. P. (2017). Multienzyme biosynthesis of dihydroartemisinic acid. Molecules 22:1422. doi: 10.3390/molecules22091422

Christianson, T. W., Sikorski, R. S., Dante, M., Shero, J. H., and Hieter, P. (1992). Multifunctional yeast high-copy-number shuttle vectors. Gene 110, 119-122. doi: 10.1016/0378-1119(92)90454-w

Easmin, F., Hassan, N., Sasano, Y., Ekino, K., Taguchi, H., and Harashima, S. (2019). gRNA-transient expression system for simplified gRNA delivery in CRISPR/Cas9 genome editing. J. Biosci. Bioeng. 128, 373-378. doi: 10.1016/j. jbiosc.2019.02.009

Entian, K. D., and Ktter, P. (2007). 25 yeast genetic strain and plasmid collections. Methods Microbiol. 36, 629-666. doi: 10.1016/s0580-9517(06)36025-4

Futcher, A. B. (1986). Copy number amplification of the 2 micron circle plasmid of Saccharomyces cerevisiae. J. Theor. Biol. 119, 197-204. doi: 10.1016/s00225193(86)80074- 1

Gao, Y., and Zhao, Y. (2013). Self- processing of ribozyme- flanked RNAs into guide RNAs in vitro and in vivo for CRISPR- mediated genome editing. J. Integr. Plant Biol. 56, 343-349. doi: 10.1111/jipb.12152

Generoso, W. C., Gottardi, M., Oreb, M., and Boles, E. (2016). Simplified CRISPRCas genome editing for Saccharomyces cerevisiae. J. Microbiol. Methods 127, 203-205. doi: 10.1016/j.mimet.2016.06.020

Giaever, G., Chu, A. M., Ni, L., Connelly, C., Riles, L., Véronneau, S., et al. (2002). Functional profiling of the Saccharomyces cerevisiae genome. Nature 418, 387-391. doi: 10.1038/nature00935

Gnügge, R., and Rudolf, F. (2017). Saccharomyces cerevisiae Shuttle vectors. Yeast 34, 205-221.

Jakounas, T., Sonde, I., Herrgard, M., Harrison, S. J., and Keasling, J. D. (2015). Multiplex metabolic pathway engineering using CRISPR/Cas9 in Saccharomyces cerevisiae. Metab. Eng. 28, 213-222. doi: 10.1016/j.ymben.2015. 01.008

Kang, C. W., Gyu, L. H., Yang, J., Hyun, N. M., Woo, S. S., and Yeol, J. G. (2018). Synthetic auxotrophs for stable and tunable maintenance of plasmid copy number. Metab. Eng. 48, 121-128. doi: 10.1016/j.ymben.2018.05.020

Karim, A. S., Curran, K. A., and Alper, H. S. (2013). Characterization of plasmid burden and copy number in Saccharomyces cerevisiae for optimization of metabolic engineering applications. Fems Yeast Res. 13, 107-116. doi: 10.1111/ 1567-1364.12016

Lee, C., Kim, J., Shin, S. G., and Hwang, S. (2006). Absolute and relative QPCR quantification of plasmid copy number in Escherichia coli. J. Biotechnol. 123, 273-280. doi: 10.1016/j.jbiotec.2005.11.014

Lian, J., Bao, Z., Hu, S., and Zhao, H. (2018). Engineered CRISPR/Cas9 system for multiplex genome engineering of polyploid industrial yeast strains. Biotechnol. Bioeng. 115, 1630-1635. doi: 10.1002/bit.26569

Lian, J., Jin, R., and Zhao, H. (2016). Construction of plasmids with tunable copy numbers in Saccharomyces cerevisiae and their applications in pathway optimization and multiplex genome integration. Biotechnol. Bioeng. 113, 24622473. doi: 10.1002/bit.26004
McQuaid, M. E., Pinder, J. B., Arumuggam, N., Lacoste, J. S. C., Chew, J. S. K., and Dobso, M. J. (2017). The yeast $2-\mu \mathrm{m}$ plasmid Raf protein contributes to plasmid inheritance by stabilizing the Rep1 and Rep2 partitioning proteins. Nucleic Acids Res. 45, 10518-10533. doi: 10.1093/nar/gkx703

Mignon, C., Sodoyer, R., and Werle, B. (2015). Antibiotic-free selection in biotherapeutics: now and forever. Pathogens 4:157. doi: 10.3390/pathogens40 20157

Misumi, Y., Nishioka, S., Fukuda, A., Uemura, T., Nakamura, M., Hoshida, H., et al. (2019). YHp as a highly stable, hyper-copy, hyper-expression plasmid constructed using a full $2-\mu \mathrm{m}$ circle sequence in cir0 strains of Saccharomyces cerevisiae. Yeast 36, 249-257. doi: 10.1002/yea.3371

Paddon, C. J., and Keasling, J. D. (2014). Semi-synthetic artemisinin: a model for the use of synthetic biology in pharmaceutical development. Nat. Rev. Microbiol. 12:355. doi: 10.1038/nrmicro3240

Paddon, C. J., Westfall, P. J., Pitera, D. J., Benjamin, K., Fisher, K., McPhee, D., et al. (2013). High-level semi-synthetic production of the potent antimalarial artemisinin. Nature 496, 528-532. doi: 10.1038/nature12051

Piroon, J., Thidathip, W., Rui, P., Preecha, P., Ussery, D. W., Jens, N., et al. (2018). Complete genomic and transcriptional landscape analysis using thirdgeneration sequencing: a case study of Saccharomyces cerevisiae CEN.PK1137D. Nucleic Acids Res. 46:e38. doi: 10.1093/nar/gky014

Rizvi, S. M. A., Prajapati, H. K., and Ghosh, S. K. (2017a). The 2 micron plasmid: a selfish genetic element with an optimized survival strategy within Saccharmyces cerevisiae. Curr. Genet. 64, 25-42. doi: 10.1007/s00294-017-0719-2

Rizvi, S. M. A., Prajapati, H. K., Nag, P., and Ghosh, S. K. (2017b). The 2- $\mu \mathrm{m}$ plasmid encoded protein Rafl regulates both stability and copy number of the plasmid by blocking the formation of the Rep1-Rep2 repressor complex. Nucleic Acids Res. 45, 7167-7179. doi: 10.1093/nar/gkx316

Ro, D.-K., Ouellet, M., Paradise, E. M., Burd, H., Eng, D., Paddon, C. J., et al. (2008). Induction of multiple pleiotropic drug resistance genes in yeast engineered to produce an increased level of anti-malarial drug precursor, artemisinic acid. BMC Biotechnol. 8:83. doi: 10.1186/1472-6750-8-83

Scott, E. W., and Baker, H. V. (1993). Concerted action of the transcriptional activators REB1, RAP1, and GCR1 in the high-level expression of the glycolytic gene TPI. Mol. Cell Biol. 13, 543-550. doi: 10.1128/mcb.13.1.543

Wang, R., Gu, X., Yao, M., Pan, C., Liu, H., Xiao, W., et al. (2017). Engineering of beta-carotene hydroxylase and ketolase for astaxanthin overproduction in Saccharomyces cerevisiae. Front. Chem. Sci. Eng. 11:89-99. doi: 10.1007/s11705017-1628-0

Xie, Z. X., Mitchell, L. A., Liu, H. M., Li, B. Z., Liu, D., Agmon, N., et al. (2018). Rapid and Efficient CRISPR/Cas9-based mating-type switching of Saccharomyces cerevisiae. G3 (Bethesda) 8, 173-183. doi: 10.1534/g3.117. 300347

Yansheng, Z., Teoh, K. H., Reed, D. W., Lies, M., Alain, G., Olson, D. J. H., et al. (2008). The molecular cloning of artemisinic aldehyde Delta11(13) reductase and its role in glandular trichome-dependent biosynthesis of artemisinin in Artemisia annua. J. Biol. Chem. 283:21501. doi: 10.1074/jbc.m8030 90200

Zeng, B.-X., Yao, M.-D., Wang, Y., Xiao, W.-H., and Yuan, Y.-J. (2020). Metabolic engineering of Saccharomyces cerevisiae for enhanced dihydroartemisinic acid production. Front. Bioeng. Biotechnol. 8:152. doi: 10.3389/fbioe.2020.00152

Conflict of Interest: The authors declare that the research was conducted in the absence of any commercial or financial relationships that could be construed as a potential conflict of interest.

Copyright (c) 2021 Zeng, Yao, Xiao, Luo, Wang and Yuan. This is an open-access article distributed under the terms of the Creative Commons Attribution License (CC BY). The use, distribution or reproduction in other forums is permitted, provided the original author(s) and the copyright owner(s) are credited and that the original publication in this journal is cited, in accordance with accepted academic practice. No use, distribution or reproduction is permitted which does not comply with these terms. 